\title{
Possibility of reusing Al-Machraya River for feeding Hawizeh marsh
}

\author{
Mahmoud Al-Khafaji ${ }^{1, *}$, Hayder Al Thamiry ${ }^{2}$ and Ala Al-Saedi ${ }^{2}$ \\ ${ }^{1}$ Building and Construction Engineering Dept., University of Technology, Baghdad, Iraq. \\ ${ }^{2}$ College of Engineering, University of Baghdad, Baghdad, Iraq.
}

\begin{abstract}
Al Machraya River was considered as one of the water feeders of Hawizeh Marsh. In 1986, the outlet of this river into the marsh was blocked and the river was used as a main channel for the East Tigris Irrigation Project near Kalat Salih. This causes significant decrease in the available water supply sources, deterioration in the water quality distribution patterns and increasing the stagnation areas within the marsh. This research aims to study the possibility of reusing this river for feeding Hawizeh Marsh. A frequency analysis study was carried out to study the maximum and minimum probable water level (MMPWL) of Tigris River at the upstream of Kalat Salih Barrage. Six statistical models; Normal distribution, Log-Normal type II, Log-Normal type III, Pearson type III, Log- Pearson type III and Gumbel type I distribution were used to estimate the MMPWL. The results show that Pearson type III and Gumbel type I distribution models are the best to fit the maximum and minimum daily water level (WL), respectively, at the upstream of the Barrage. The estimated MMPWL were compared to the required WL in Hawizeh Marsh. The difference between Tigris River and Hawizeh Marsh water levels were found to be not operative to cause a significant flow toward the marsh. Therefore, Al Machraya River cannot be used to feed Hawizeh Marsh.
\end{abstract}

\section{Introduction}

Al Machraya River was considered as one of the water feeders of Hawizeh Marsh. Its design discharge is 40m3/s. Since 1986, this river is used to irrigate the East Tigris Irrigation Project which is located near Kalat Salih. The intake of this river is located at $4 \mathrm{~km}$ upstream of Kalat Salih Barrage Fig.1. This barrage is located at E

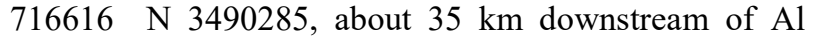
Amarah City. Kalat Salih Barrage is controlled by Al Amarah Barrage which controlled the water levels in Tigris River downstream of Al Amarah Barrage. Operation of Kalat Salih Barrage can be grouped into three categories according to the period and level of operation; 1979 to 1990 , which is the high water level period, 1990 to 2003, which is the low water level period (to reduce the participation of Southern Iraqi marshlands) and 2004 till now, which is the moderate level period (in order to rehabilitate the southern Iraqi marshlands).

The decrease in water resources that feed the marsh causes significant deterioration in the ecological system of the marsh. Sustainability of this system is highly affected by the status of water quality within the marsh in terms of pollution levels and distribution patterns. Location of Al Machraya River outlet into the marsh can contribute effectively to improve the water quality distribution patterns and decrease the stagnation areas within the marsh. In order to reuse this river to feed the marsh, the available water levels in Tigris River at the inlet of this river must be enough to ensure flowing of the required discharge into the marsh. Accordingly, it is of important to study the possibility of satisfying the feeding requirements with the available water level at the inlet and outlet of the river.

This research aims to conduct a comparative study for the maximum and minimum probable water level (MMPWL) in Tigris River at the inlet of Al Machraya River and in the marsh at the outlet of this river. This can be achieved through carrying out a frequency analysis study for the MMPWL at the upstream of Kalat Salih Barrage. For this purpose, statistical distribution models of the maximum and minimum daily water level should be tested to specify and then apply the best fit models. Results of this analysis can be compared with the water levels at the outlet of the river, which are required to achieve the positive operational control of the marsh to ensure the continuity of the ecological system balance of Hawizeh Marsh.

The maximum and minimum daily water levels in Kalat Salih Barrage as measured by Ministry of Water Resources (MoWR) [7] are listed in Table 1.

The water levels in Hawizeh Marsh, which are required to achieve the positive operational control of the marsh to ensure the continuity of the ecological system balance of Hawizeh Marsh are shown in Fig.2, [4].

*Corresponding author: 41100@uotechnology.edu.iq 


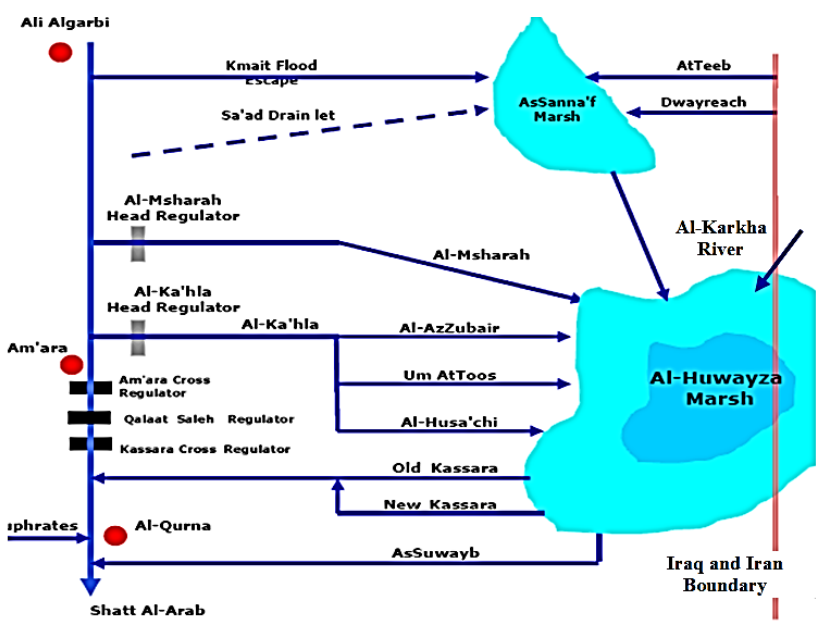

Fig. 1. Schematic diagram of the study area [4].

Table 1. The Maximum and Minimum daily water levels in Kalat Salih barrage [7].

\begin{tabular}{|c|c|c|}
\hline \multirow{2}{*}{ Year } & \multicolumn{2}{|c|}{ Water Surface Elevation (m amsl) } \\
\cline { 2 - 3 } & Maximum & Minimum \\
\hline 1996 & 6.40 & 4.00 \\
\hline 1997 & 6.50 & 4.40 \\
\hline 1998 & 6.80 & 4.60 \\
\hline 1999 & 6.80 & 4.40 \\
\hline 2000 & 6.70 & 4.10 \\
\hline 2001 & 6.70 & 4.10 \\
\hline 2002 & 6.30 & 4.40 \\
\hline 2003 & 6.40 & 4.40 \\
\hline 2004 & 7.22 & 5.20 \\
\hline 2005 & 7.06 & 5.61 \\
\hline 2006 & 7.15 & 5.40 \\
\hline 2007 & 5.90 & 4.60 \\
\hline 2008 & 5.12 & 4.12 \\
\hline 2009 & 6.75 & 4.25 \\
\hline 2010 & 5.37 & 4.03 \\
\hline 2011 & 5.30 & 3.99 \\
\hline 2012 & 5.60 & 3.55 \\
\hline 2013 & 4.90 & 3.40 \\
\hline 2014 & 5.42 & 3.77 \\
\hline 2015 & 4.20 & 4.25 \\
\hline
\end{tabular}

\section{Material and methods}

\subsection{Frequency analysis}

The MMPWL in Tigris River at the upstream of Kalat Salih Barrage were determined by using six statistical models. These models are; Normal distribution [2], LogNormal type II [2], Log-Normal type III [2], Pearson type III, Log- Pearson type III [8] and Gumbel type I distribution [6]. These water levels were estimated for return periods of $5,10,20,50$ and 100 years. The minimum and maximum daily water levels of 20 years for the period 1996 to 2015 were used to perform the frequency analysis, as shown in Table 1.

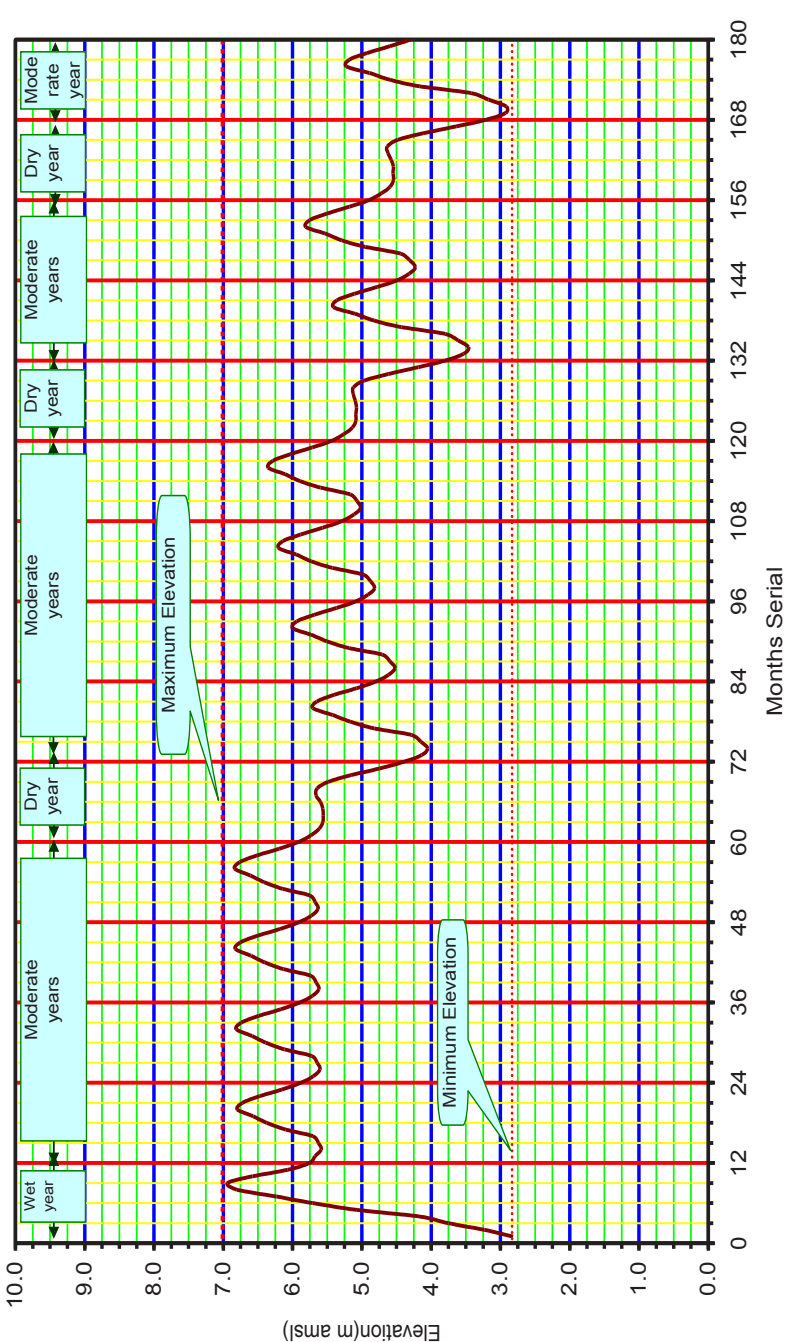

Fig. 2. Monthly variation of water level within Al Huwayza Marsh [4].

The parameters of distributions which are; Mean $(\bar{X})$, Standard deviation $\left(S_{d}\right)$, Coefficient of variation $\left(C_{v}\right)$, Skewness Coefficient $\left(C_{S}\right)$ and Kurtosis Coefficient $\left(C_{k}\right)$ were estimated by using Method of Moment. These parameters give an indication about which distribution should be accepted [5]. This data has a confidence level between $90-95 \%$ according to the method of reading and the actual situation of existing staff gages in site.

\subsection{Graphical analysis of fit}

There is no exact answer to the question 'Which distribution is best for representing the minimum and maximum water level?'. All the distributions may be fitted and plotted as cumulative density function (CDF) on the normal or log-normal probability papers and may give an answer to such a question [1]. To specify the best statistical distribution models of the maximum and minimum water levels at the upstream of Kalat Salih Barrage, the six statistical distribution models were tested. The cumulative density function (CDF) of these models were fitted and plotted on the normal or lognormal probability papers. 


\subsection{Goodness of fits}

A set of data or observations can be described by using some statistical parameters such as the mean and standard deviation. These parameters are estimated from samples. If the samples are unrepresentative then the estimates may be too high or too low. The estimations cannot be used if they differ from expected values by more than certain prescribed limits. Therefore, it is necessary to test the statistics to specify significance of the difference. Such tests are called the test of significance. According to this test, the smallest values of standard error (SE), root mean square error (RMSE) and bias (BIAS) lead to the best fit.

\section{Results and discussion}

The obtained parameters of distribution for the maximum and minimum water levels in Tigris River at the upstream Kalat Salih Barrage are listed in Table 2.

Table 2. Obtained parameters of distribution for minimum and maximum water levels at Tigris River upstream Kalat Salih Barrage.

\begin{tabular}{|c|c|c|}
\hline Parameter & $\begin{array}{c}\text { Maximum } \\
\text { water level }\end{array}$ & $\begin{array}{c}\text { Minimum } \\
\text { water level }\end{array}$ \\
\hline Mean $(\overline{\bar{X}})$ & 6.13 & 4.33 \\
\hline Standard deviation $\left(S_{d}\right)$ & 0.849 & 0.561 \\
\hline Coefficient of variation $\left(C_{v}\right)$ & 0.084 & 0.132 \\
\hline Skewness Coefficient $\left(C_{s}\right)$ & -0.680 & 0.816 \\
\hline Kurtosis Coefficient $\left(C_{k}\right)$ & 2.672 & 3.466 \\
\hline $\begin{array}{c}\text { Mean of logarithmic water levels } \\
(\bar{Y})\end{array}$ & 1.803 & 1.458 \\
\hline $\begin{array}{c}\text { Standard deviation for } \\
\left.\text { logarithmic water levels ( } S_{d y}\right)\end{array}$ & 0.147 & 0.126 \\
\hline $\begin{array}{c}\text { Coefficient of variation for } \\
\text { logarithmic water levels }\left(C_{v y}\right)\end{array}$ & 0.054 & 0.078 \\
\hline $\begin{array}{c}\text { Skewness Coefficient for } \\
\text { logarithmic water levels }\left(C_{s y}\right)\end{array}$ & -0.796 & 0.386 \\
\hline $\begin{array}{c}\text { Kurtosis Coefficient for } \\
\text { logarithmic water levels }\left(C_{k y}\right)\end{array}$ & 2.771 & 2.897 \\
\hline
\end{tabular}

The normal distribution sample estimates of the skewness and kurtosis for the maximum water levels are -0.680 and 2.672 , whereas for minimum water levels are 0.816 and 3.466 , respectively. These parameters are neither close to zero nor close to 3 . Therefore, the Normal distribution may not be a suitable distribution for the maximum and minimum daily water level.

The computed skewness of Log-Normal type II distribution for the maximum and minimum water levels $\left(\mathrm{Cs}=3 \mathrm{Cv}+\mathrm{Cv}^{3}\right.$ according to [3] $)$ are 0.40 and 0.25 respectively, which are quite incomparable to $\mathrm{Cs}=-$ 0.680 and 0.816 . Furthermore, $\mathrm{C}_{\mathrm{sy}}$ for maximum and minimum water levels are -0.796 and 0.386 , respectively, which are different from zero. While $\mathrm{C}_{\mathrm{ky}}$ of logarithmic distribution model for maximum and minimum water levels are 2.771 and 2.897 , respectively which are close to 3.000 . This distribution is not satisfying all the conditions. Therefore, it is not the suitable distribution.

The accuracy of log-normal type III distribution was checked graphically or from the goodness of fit tests, as this distribution has no limitations.

For Log-Pearson type III distribution, the skewness coefficient of logarithm of data should be greater than zero [3]. Since the sample estimates of the population skewness for maximum and minimum water levels are 0.796 and 0.386 , respectively, which are greater than zero for minimum water level, then the Log-Pearson type III distribution can be accepted for the minimum water levels only.

The best values of skewness and kurtosis for Gumbel distribution are 1.14 and 5.4, respectively [3]. The computed sample estimates of the skewness and kurtosis are not close to Gumbels skewness and kurtosis. Also, Gumbel distribution or any of the other distributions cannot refuse until checking the result of those distributions with the available data.

The plotted cumulative density functions (CDF) on the normal or log-normal probability papers for the considered six models are shown in Fig.s 3 to 14. The maximum and minimum water levels at Tigris River upstream Kalat Salih Barrage for different return periods and distributions are given in Table 3. The maximum water level is $7.00,7.14$ and $7.23 \mathrm{~m}$ amsl for return period of 20, 50 and 100 years, respectively. These levels may occur in wet years only, during which the water level at Hawizeh Marsh will be at maximum level, $7 \mathrm{~m}$ amsl. The total difference between Tigris River and Hawizeh Marsh water levels will not be operative to cause a significant flow towards the Marsh.

Kalat Salih Barrage is controlled by Al Amarah Barrage and there are many irrigation projects along the reach between those two barrages. So, the water levels upstream Kalat Salih Barrage will not reach any extreme values. Additionally, in flood season, Kumait escape (40 $\mathrm{km}$ upstream of $\mathrm{Al}$ Amara City, with maximum discharge of $400 \mathrm{~m}^{3} / \mathrm{sec}$ and a weir crest at $8 \mathrm{~m}$ amsl) will divert large share of the flood discharge towards Hawizeh Marsh throughout AsSanna'f Marsh.

Consequently Al Machraya River cannot be used as a feeder for Hawizeh Marsh under the present conditions of the Tigris River and Hawizeh Marsh. 


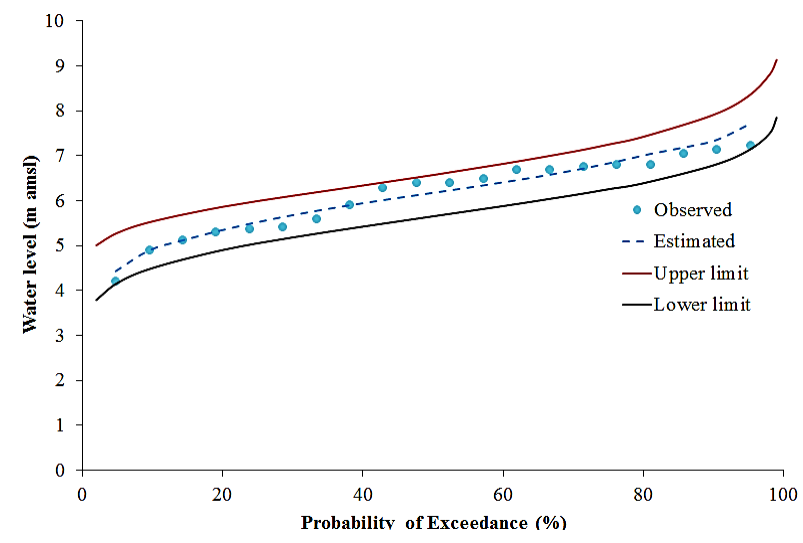

Fig. 3. Normal Plot of Maximum Daily Water Level with 95\% confidence intervals.

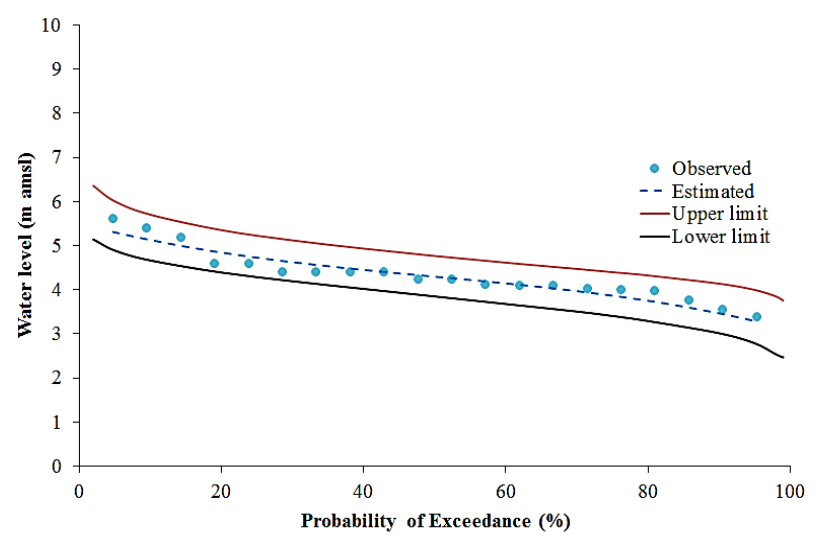

Fig. 4. Normal Plot of Minimum Daily Water Level with 95\% confidence intervals.

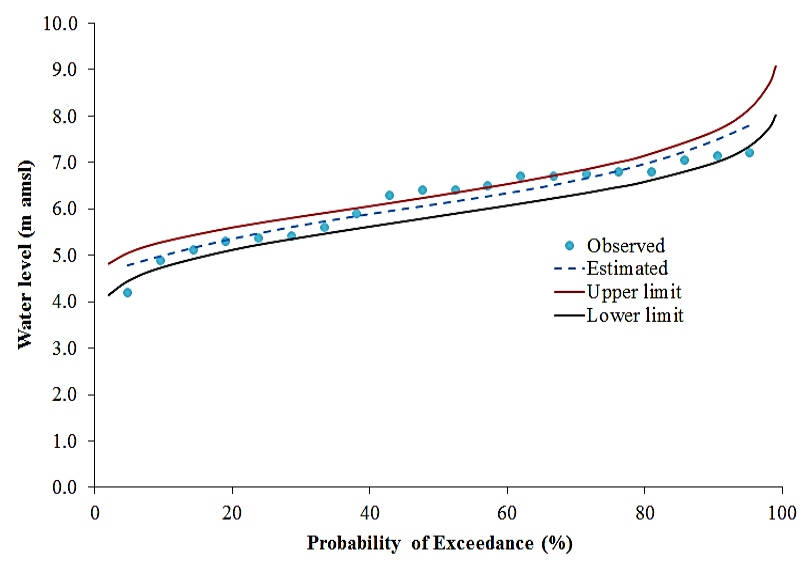

Fig. 5. Log- Normal Type 2 Plot of Maximum Daily Water

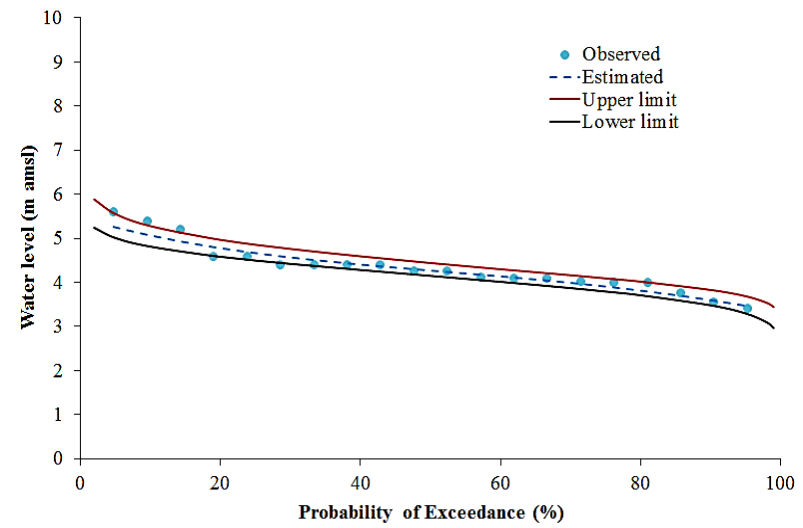

Fig. 6. Log- Normal Type 2 Plot of Minimum Daily Water Level with $95 \%$ confidence intervals.

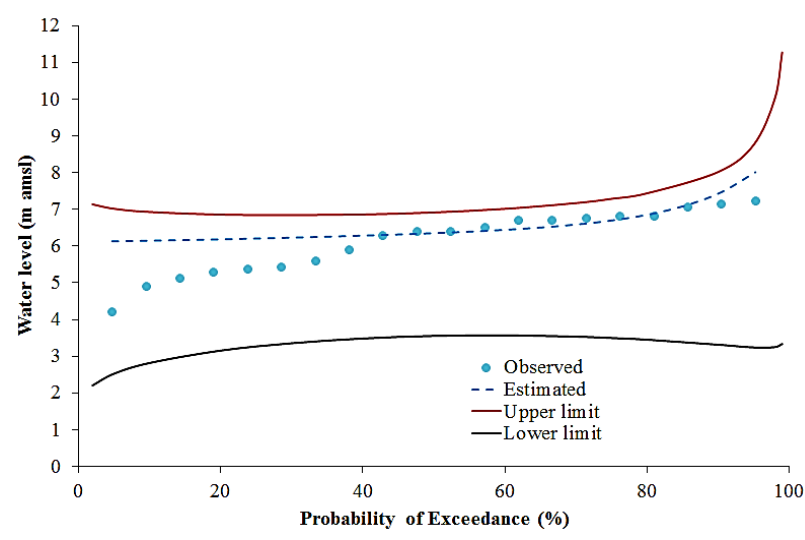

Fig. 7. Log- Normal Type 3 Plot of Maximum Daily Water Level with $95 \%$ confidence intervals and $A=6.1 \mathrm{~m}$ amsl.

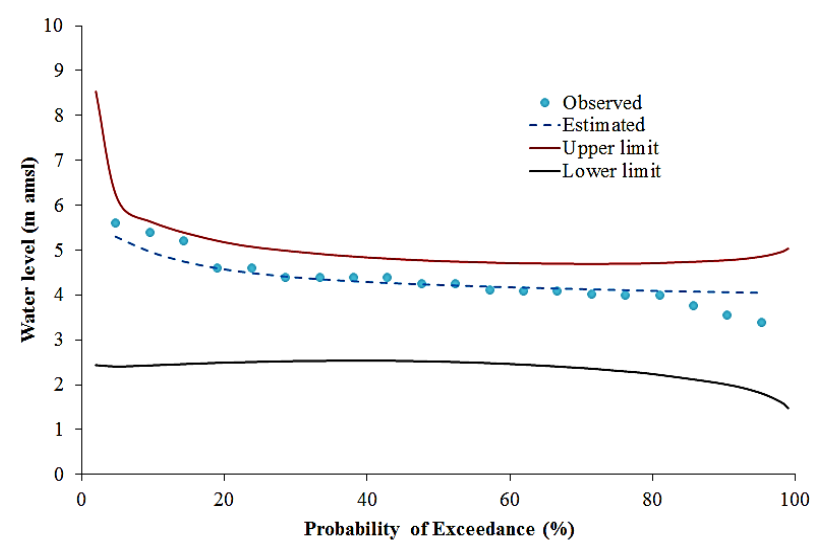

Fig. 8.Log- Normal Type 3 Plot of Minimum Daily Water Level with $95 \%$ confidence intervals and $\mathrm{A}=4.02 \mathrm{~m}$ amsl. 


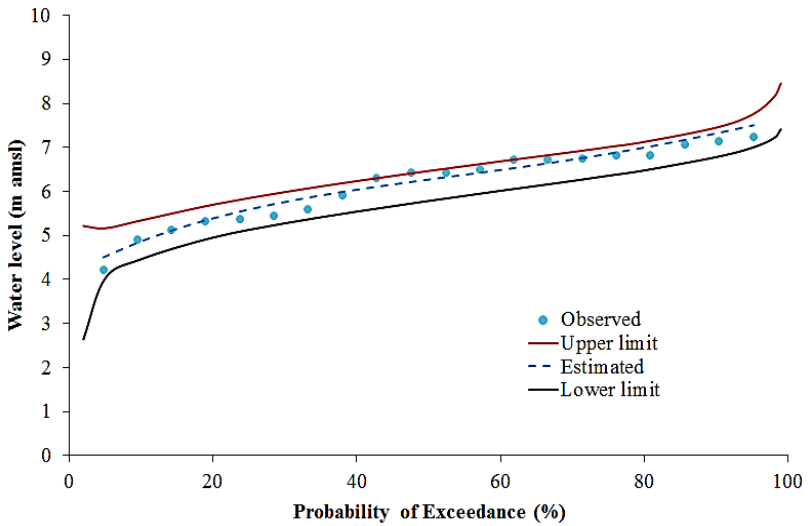

Fig. 9. Person Type 3 Plot of Maximum Daily Water Level with $95 \%$ confidence intervals.

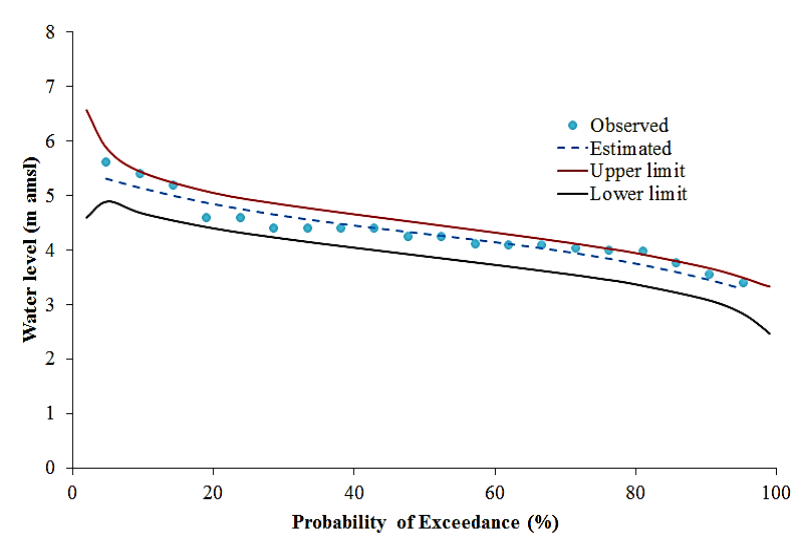

Fig. 10. Person Type 3 Plot of Minimum Daily Water Level with $95 \%$ confidence intervals.

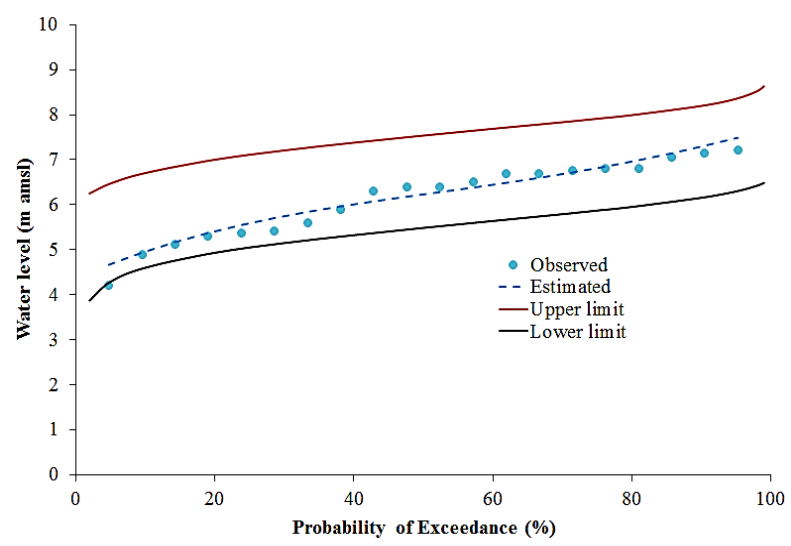

Fig. 11. Log-Person Type 3 Plot of Maximum Daily Water Level with $95 \%$ confidence intervals.

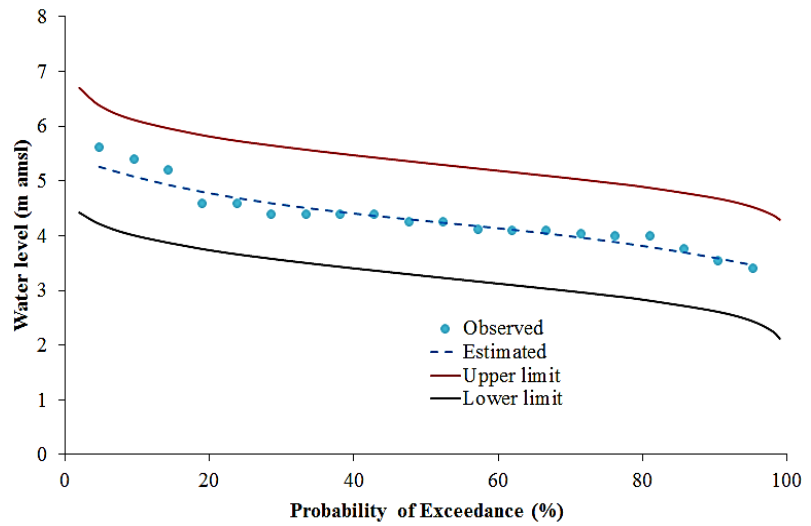

Fig. 12. Log-Person Type 3 Plot of Minimum Daily Water Level with $95 \%$ confidence intervals

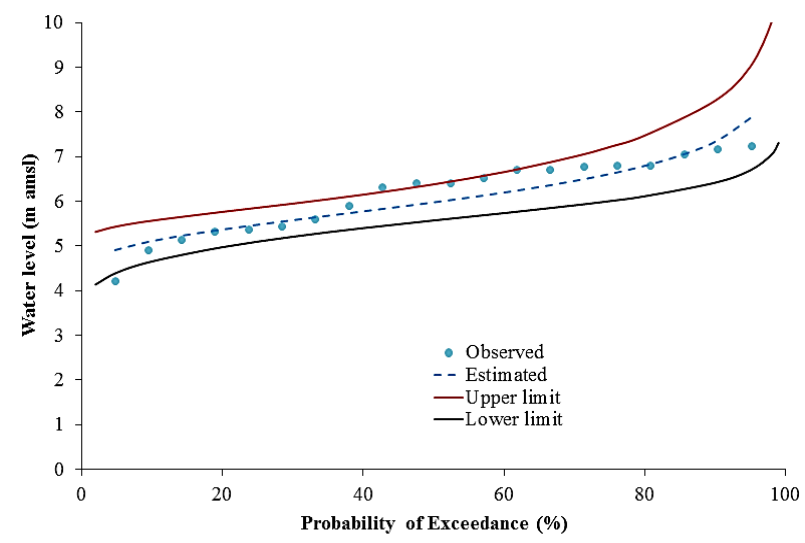

Fig. 13. Gumbel type1 Plot of Maximum Daily Water Level with $95 \%$ confidence intervals

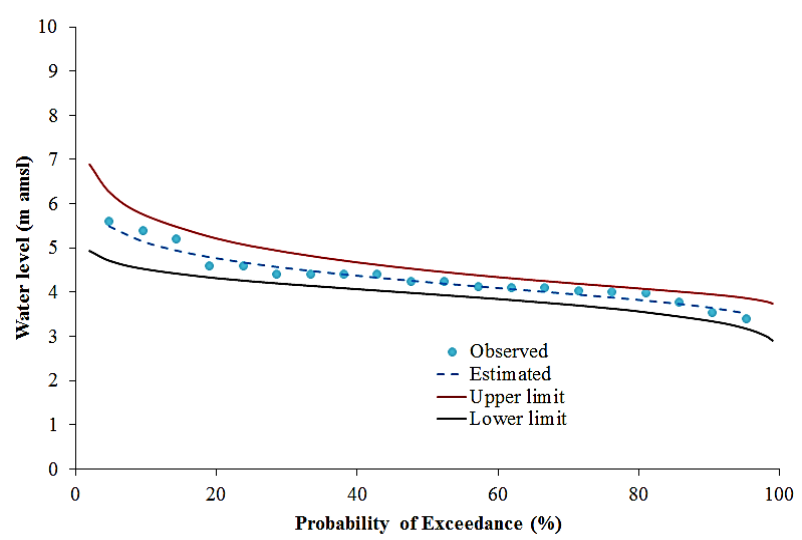

Fig. 14. Gumbel type1 Plot of Minimum Daily Water Level with $95 \%$ confidence intervals. 
Table 3. Water Level (mamsl) versus return Periods of six models.

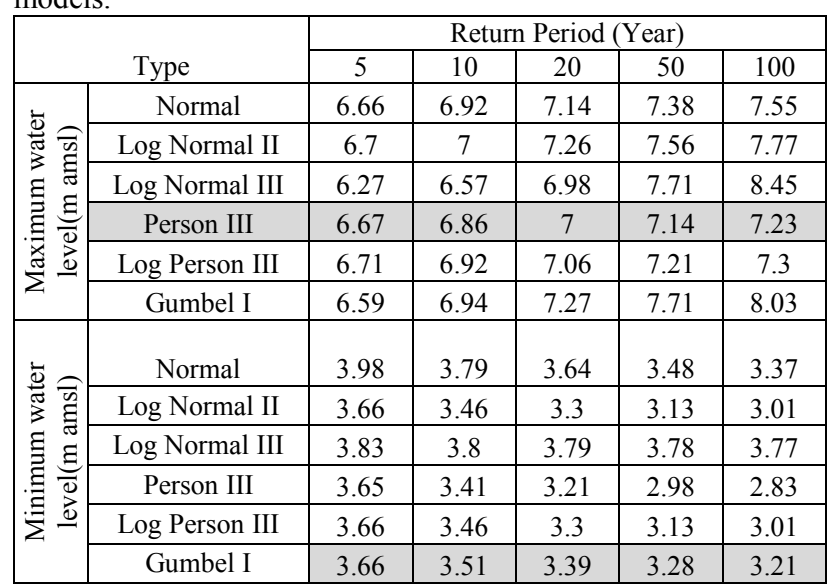

\section{Conclusions}

The decision of reusing Al Machraya River for feeding Hawizeh Marsh in terms of hydrology is based on the satisfactory water level to the flow requirements. This can be studied through comparing the water levels in Tigris River at the inlet of Al Machraya River with that in the marsh at the outlet of the river. The probable maximum and minimum water level at the inlet of the river were obtained through carrying out a frequency analysis of the daily maximum and minimum water levels for the period from 1996 to 2015. This analysis involves testing six statistical distribution models to specify the best fit model. It is found that Pearson type III distribution is the best model for estimating the probable maximum daily water levels. While Gumble type I distribution is the best model for estimating the probable minimum daily water levels. The estimated probable maximum water levels at the inlet of the river upstream Kalat Salih Barrage for the return period of 5, 10, 20, 50 and 100 years by using the best fit distributions are $6.67 \pm$ $0.32,6.86 \pm 0.16,7.00 \pm 0.12,7.14 \pm 0.13$ and $7.23 \pm$ 0.16 mamsl. Whereas, the minimum water levels for the same return periods are $3.66 \pm 0.31,3.51 \pm 0.37,3.39 \pm$ $0.42,3.28 \pm 0.48$ and $3.21 \pm 0.52 \mathrm{~m}$ amsl.

The maximum water levels usually occur during the wet years only when the water level at Hawizeh Marsh is at its maximum level, $7 \mathrm{~m}$ amsl. The total difference in water levels between the inlet and outlet of the river are not significant to satisfy the requirements of flow from Tigris River to Hawizeh Marsh via Al Machraya River. Accordingly, Al Machraya River cannot be used as a feeder for Hawizeh Marsh under the present conditions of Tigris River and Hawizeh Marsh.

\section{References}

1. R. I. Levin, D. S. Rubin, Wesley Publishing Company(1994).

2. P.B. Bedient, W. C. Huber, Addison-Wesley publication Company (1992).

3. C. Walck, Particle Physics Group Fysikum University of Stockholm (e-mail: walck@physto.se) (2007).
4. CRIMW (Center for the Restoration of the Iraq Marshlands and Wetlands), Ministry of Water Resources, Baghdad, Iraq (2006).

5. D.George, M. Mallery17.0 update (10a ed.) Boston: Pearson, (2010).

6. M. U. Ibrahim, MSc. thesis, College of Engineering. , University of Baghdad (1994).

7. MoWR (Ministry of Water Resources), unpolished documents, Ministry of Water Resources, Baghdad, Iraq (2016).

8. S. K. Gary, New Dehli Khanna (1993). 